\title{
Enhancing the Productivity of Wire Electrical Discharge Machining Toward Sustainable Production by using Artificial Neural Network Modelling
}

\author{
M.A.M. Zakaria1, R. Izamshah², M.S. Kasim³ ${ }^{3}$, M.H. Ibrahim ${ }^{4}$ \\ 1,2,3Advanced Materials and Precision Engineering, \\ Advanced Manufacturing Centre (AMC), \\ Universiti Teknikal Malaysia Melaka, \\ 76100 Durian Tunggal, Melaka, Malaysia. \\ ${ }^{4}$ Mechanical Engineering Department, \\ Politeknik Merlimau Melaka, \\ Jalan Jasin,77300 Merlimau, Melaka, \\ Malaysia.
}

Email:1akmalzak@student.utem.edu.my, 2izamshah@utem.edu.my, 3shahir@utem.edu.my, ${ }^{4}$ mhalim@pmm.edu.my

\begin{abstract}
Sustainability plays an important role in manufacturing industries through economically-sound processes that able to minimize negative environmental impacts while having the social benefits. In this present study, the modeling of wire electrical discharge machining (WEDM) cutting process using an artificial neural network (ANN) for prediction has been carried out with a focus on sustainable production. The objective was to develop an ANN model for prediction of two sustainable measures which were material removal rate (as an economic aspect) and surface roughness (as a social aspect) of titanium alloy with ten input parameters. By concerning environmental pollution due to its intrinsic characteristics such as liquid wastes, the water-based dielectric fluid has been used in this study which represents an environmental aspect in sustainability. For this purpose, a feed-forward backpropagation ANN was developed and trained using the minimal experimental data. The other empirical modelling techniques (statistics based) are less in flexibility and prediction accuracy. The minimal, vague data and nonlinear complex input-output relationship make this ANN model simple and perfects method in the manufacturing environment as well as in this study. The results showed good agreement with the experimental data confirming the effectiveness of the ANN approach in the modeling of material removal rate and surface roughness of this cutting process.
\end{abstract}

Keywords: WEDM, ANN, Sustainability, Productivity, Water-based dielectric. 


\section{INTRODUCTION}

Wire electrical discharge machining (WEDM) is one of a versatile advanced machining processes, it utilizes the principle of energy conversion by generating a series of electrical sparks in an extremely brief time then turns it into thermal energy where the material is eroded and removed. Since WEDM process involves no physical contact between the workpiece and the electrode wire, no cutting force is produced. It enables the cutting of intricate and delicate shapes as well as materials that are difficult to cut. Therefore, this process has been widely used in the automotive, aerospace and medical industries $[1,2]$. The most significant performance outputs in WEDM are material removal rate (MRR) which represents process productivity and surface roughness represents the product quality. The surface quality in products manufactured is really critical, especially in aerospace applications which it also embody the reliability of the components [3]. This surface roughness should be kept low and able to control during parts machining. In joining two parts components to form a final product, the same value of surface roughness should compromise each other to form sealing ability.

With constant environmental awareness, the increase in product quantity with high quality has attracted lots of researchers. One way to pursue a sustainable production in WEDM is employing non-hydrocarbon oils based dielectric to reduce the effect of environmental issues [4, 5]. According to Kellen et al. [6], the usage of WEDM process could impact as much $23 \%$ to the environment in the case of hydrocarbon oil consumption and the end of life treatment of the dielectric. Therefore, the hydrocarbon oil dielectrics could be replaced by water-based dielectrics such as plain water, water mixed with organic compounds or de-ionized water as suggested by Kellen et al. [6] and Kou and Han [7], which could help to reduce the environmental impacts and related human health risks.

However, the nonlinear nature of the input-output variables of WEDM cutting parameters [8] with the drawbacks of water-based dielectrics could produce rough surface and damage to the product sub-surface $[9,10]$. Many attempts have been made to model the WEDM process in term of cutting with smooth surface finish and possess high MRR [11-13]. However, the process remains challenging as minor changes in any of the parameters may cause an effect to the product performance output.

Therefore, it is vital for the researchers to model and compute the relationship between input parameters and the outputs responses. As a result, several prediction techniques have been employed such as factorial design, statistical regression and artificial intelligence-based models [14, 15]. In this case, the factorial design and statistical regression known as empirical modelling techniques are unable to describe the nonlinear complex relationship between input parameters and outputs responses. As the alternative solution, the artificial intelligence-based models have lot of interest in developing predictive models because they have the capability to handle multiple variables with vague and incomplete data $[16,17]$. 
The applications of ANN modelling in WEDM process is still new and there are no studies towards the sustainable production to the best knowledge of the authors. Shandilya et al. [18] employed ANN and statistic approach for the estimation of the average cutting speed in the machining of $\mathrm{SiCp} / \mathrm{Al} 6061$ composites with WEDM and they found that the prediction accuracy of ANN model was about three times better than statistical model. Devarasiddappa et al. [19] applied ANN model to predict the surface roughness in WEDM of aerospace alloy with accuracy as much $93.62 \%$. They also mentioned that this ANN technique could further be develop for artificial intelligence based on-line learning system.

Therefore, aligned with the direction of sustainability production that covers three pillars of sustainability which economic, environmental and social performance [20], this study employed water-based WEDM (as environmental aspect) for cutting aerospace grade titanium alloy using ANN feed-forward backpropagation modelling approach. This model predicted the MRR (as economic aspect) and surface roughness (as social aspect) based on input and output parameters.

\section{MATERIALS AND METHODS}

In this study, the experiment was carried out using the Mitsubishi RA90 machine (Figure 1) to model the cutting process based on the ANN approach. There were 10 parameters (factors) involved and described in detail in Table 1. The measured performances were MRR and surface roughness as the target function (response, output).

Since the influences of parameters on the selected target function are nonlinear and manufacturers only have recommendations on parameter limited to certain materials, an experiment with modified Taguchi L12 orthogonal array approach as design matrix was set up (Table 2). The new design matrix was able to eliminate the wire ruptured during machine processing and offer good agreement among the parameters, which promote a successful cutting process. However, the collected data from this modified design faced an error when analysed through statistical approach for obtaining the mathematical model for prediction, thus, feed-forward backpropagation ANN is employed. This method has advantages to have prediction potentials for non-experimental pattern as stated by Muthukrishnan and Davim [21] and additionally this ANN methodology consumes lesser time giving higher accuracy.

The details of experimental conditions used in the experiment are shown in Table 3. All the trials were conducted with a similar machine tool, electrode type, measurement instruments and the other constant parameters.

Theoretical equation (1) was used to calculate for MRR. K is the kerf width ( $\mathrm{mm})$, h is the workpiece thickness ( $\mathrm{mm}$ ) and FR is the cutting speed $(\mathrm{mm} / \mathrm{min})$. The kerf width was measured by Meiji Zoom stereo microscope. 


$$
M R R=\operatorname{KhFR}\left(\mathrm{mm}^{3} / \mathrm{min}\right)
$$

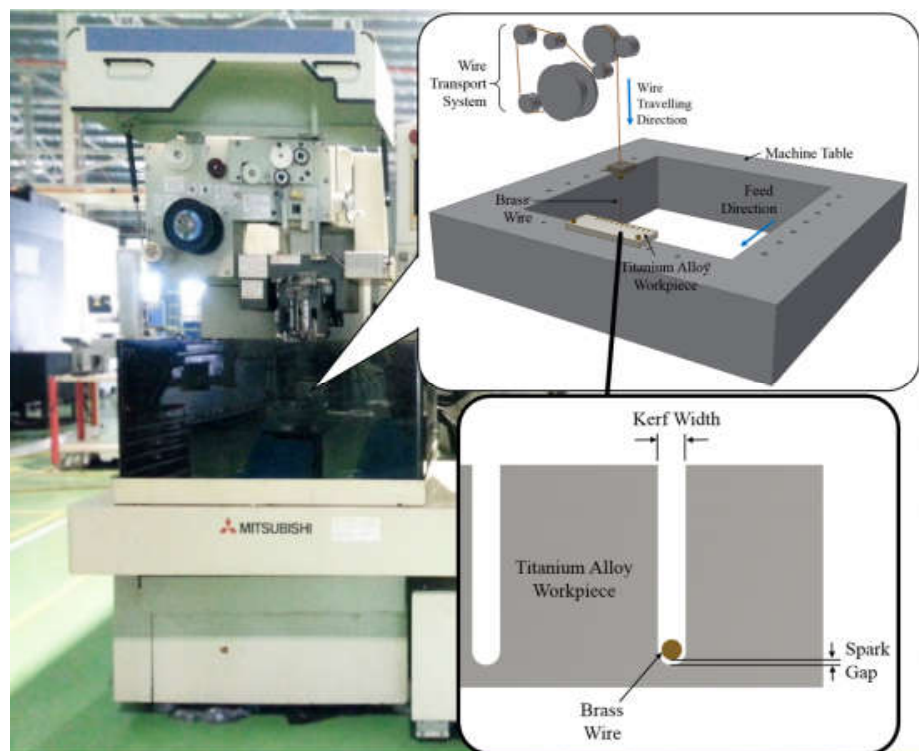

Figure 1. Experimental setup of WEDM in cutting the titanium alloy

Table 1. Cutting parameters, ranges and their descriptions

\begin{tabular}{|c|c|c|}
\hline $\begin{array}{c}\text { Cutting } \\
\text { Parameters }\end{array}$ & $\begin{array}{l}\text { Level } \\
\text { and } \\
\text { Range }\end{array}$ & Descriptions \\
\hline $\begin{array}{l}\text { Voltage open, } \\
\text { Vo }\end{array}$ & $\begin{array}{l}4-16 \\
\text { Notch }\end{array}$ & $\begin{array}{l}\text { This parameter controls the height of the gap voltage } \\
\text { during no-load. Voltage increases for larger notch } \\
\text { number. }\end{array}$ \\
\hline $\begin{array}{c}\text { Power Setting, } \\
\text { IP }\end{array}$ & $\begin{array}{c}3-12 \\
\text { Notch }\end{array}$ & $\begin{array}{l}\text { This parameter controls the size of the peak current } \\
\text { that flows the gap. }\end{array}$ \\
\hline Off Time, OFF & $\begin{array}{c}1-10 \\
\text { Notch }\end{array}$ & $\begin{array}{l}\text { This parameter controls the time between end of } \\
\text { discharge and new voltage applied. }\end{array}$ \\
\hline $\begin{array}{l}\text { Stabilizer A, } \\
\text { SA }\end{array}$ & 2-5 Notch & $\begin{array}{l}\text { This parameter controls the cutting stability and is used } \\
\text { to finely adjust the current. }\end{array}$ \\
\hline $\begin{array}{l}\text { Stabilizer B, } \\
\text { SB }\end{array}$ & $\begin{array}{l}3-15 \\
\text { Notch }\end{array}$ & $\begin{array}{l}\text { This parameter controls the cutting stability and is used } \\
\text { to finely adjust the off time. }\end{array}$ \\
\hline Stabilizer E, SE & 1-5 Notch & $\begin{array}{l}\text { This parameter controls the cutting stability. As the } \\
\text { notch value increase, the cutting become slower, but } \\
\text { wire is difficult to break. }\end{array}$ \\
\hline $\begin{array}{l}\text { Voltage Gap, } \\
\text { VG }\end{array}$ & $\begin{array}{l}42-70 \\
\text { Volts }\end{array}$ & $\begin{array}{l}\text { This parameter controls the average cutting voltage } \\
\text { used as a target value when cutting with optimum feed. }\end{array}$ \\
\hline $\begin{array}{l}\text { Wire Speed, } \\
\text { WS }\end{array}$ & $\begin{array}{l}12-14 \\
\text { Notch }\end{array}$ & $\begin{array}{c}\text { This parameter controls the wire feed rate. The higher } \\
\text { the value, the faster the wire feed rate. }\end{array}$ \\
\hline $\begin{array}{c}\text { Wire Tension, } \\
\text { WT }\end{array}$ & $\begin{array}{l}11-14 \\
\text { Notch }\end{array}$ & $\begin{array}{l}\text { This parameter controls the wire tension. The higher } \\
\text { the value, the higher the tension of wire. }\end{array}$ \\
\hline Feedrate & $\begin{array}{c}0.15-0.25 \\
\mathrm{~mm} / \mathrm{min}\end{array}$ & $\begin{array}{l}\text { This parameter controls the feed rate of machine table. } \\
\text { The higher the value, the faster the movement of } \\
\text { machine table. }\end{array}$ \\
\hline
\end{tabular}


Table 2. Experimental design matrix

\begin{tabular}{|c|c|c|c|c|c|c|c|c|c|c|}
\hline Trials & $\begin{array}{c}\text { Vo } \\
\text { (Notch) }\end{array}$ & $\begin{array}{c}\text { IP } \\
\text { (Notch) }\end{array}$ & $\begin{array}{c}\text { OFF } \\
\text { (Notch) }\end{array}$ & $\begin{array}{c}\text { SA } \\
\text { (Notch) }\end{array}$ & $\begin{array}{c}\text { SB } \\
\text { (Notch) }\end{array}$ & $\begin{array}{c}\text { SE } \\
\text { (Notch) }\end{array}$ & $\begin{array}{c}\text { VG } \\
\text { (Volts) }\end{array}$ & $\begin{array}{c}\text { WS } \\
\text { (Notch) }\end{array}$ & $\begin{array}{c}\text { WT } \\
\text { (Notch) }\end{array}$ & $\begin{array}{c}\text { Feedrate } \\
\text { (mm/min) }\end{array}$ \\
\hline 1 & 16 & 6 & 1 & 3 & 11 & 5 & 47 & 12 & 11 & 0.25 \\
\hline 2 & 16 & 7 & 1 & 5 & 9 & 5 & 52 & 12 & 11 & 0.25 \\
\hline 3 & 16 & 6 & 1 & 4 & 9 & 5 & 42 & 12 & 11 & 0.25 \\
\hline 4 & 12 & 4 & 1 & 2 & 12 & 1 & 44 & 12 & 13 & 0.25 \\
\hline 5 & 9 & 4 & 1 & 2 & 15 & 1 & 57 & 12 & 13 & 0.25 \\
\hline 6 & 9 & 4 & 1 & 2 & 15 & 1 & 57 & 12 & 13 & 0.25 \\
\hline 7 & 10 & 12 & 1 & 2 & 15 & 1 & 55 & 14 & 13 & 0.25 \\
\hline 8 & 8 & 4 & 1 & 2 & 12 & 1 & 48 & 12 & 13 & 0.25 \\
\hline 9 & 5 & 3 & 10 & 2 & 3 & 1 & 70 & 2 & 3 & 0.15 \\
\hline 10 & 6 & 3 & 10 & 2 & 5 & 1 & 70 & 12 & 13 & 0.15 \\
\hline 11 & 8 & 3 & 10 & 2 & 3 & 1 & 50 & 12 & 14 & 0.15 \\
\hline 12 & 4 & 3 & 8 & 2 & 3 & 1 & 70 & 12 & 13 & 0.25 \\
\hline
\end{tabular}

Table 3. Machining system, workpiece and measuring equipment

\begin{tabular}{|c|l|}
\hline Machine Tool & $\begin{array}{l}\text { Non-submersible type machine, Mitsubishi RA90, Pulse generator } \\
=\text { Transistor, Maximum gap current =50 Ampere, Nozzle distance } \\
\text { from workpieces = upper }(0.3 \mathrm{~mm}) \text { and lower }(0.1 \mathrm{~mm})\end{array}$ \\
\hline Electrode Wire & Brass wire, Diameter 0.25 mm, Tensile Strength $1000 \mathrm{~N} / \mathrm{mm}^{2}$ \\
\hline Workpiece & $\begin{array}{l}\text { Aerospace grade of Ti-6Al-4V, Thickness = 10mm, Hardness= } \\
36 \mathrm{HRC}[22] \\
\text { Chemical Composition }(\% \text { by weight): [Aluminium, 6.9; } \\
\text { Vanadium, 4.1; Carbon, 0.10; Iron, 0.30; Silicon, 0.15; Oxygen, } \\
0.20 ; \text { Nitrogen, 0.05; Hydrogen, 0.015] }\end{array}$ \\
\hline Dielectric Fluid & $\begin{array}{l}\text { Deionized water, 0.2 MPa constant pressure jet, resistivity of the } \\
\text { dielectric fluid is 6 x } 10^{4} \Omega \mathrm{cm}\end{array}$ \\
\hline Measuring & $\begin{array}{l}\text { Mitutoyo SJ-301 portable surface roughness tester 0.8 cut-off } \\
\text { Equipment }\end{array}$ \\
\hline
\end{tabular}

\section{ARTIFICIAL NEURAL NETWORK MODELLING}

ANN is a computational artificial intelligence-based model that works in principle of the structure and functions of biological neural networks. This method is capable to model a wide diversity of problems. In manufacturing process, the satisfactory empirical and analytic physical models are limited, thus the neural network offers an excellent solution approach [23]. In this network model, a neuron is a basic unit that connected each other by links that known as synapses, each of synapses coupled with weight factor [24].

\subsection{ANN Architecture}

In this study, the ANN architecture was developed and designed by using Matlab Neural Network Toolbox in Matlab R2015a. Details on the neural network modeling approach were described in Table 4. The first step in the ANN prediction model development was to produce an input-output 
database required for training and testing purpose through the experimental works. The experimental plan was carried work using the Taguchi orthogonal array modified model.

Table 4. Specification of the trained neural network

\begin{tabular}{|c|c|}
\hline Tool & Matlab R2015a \\
\hline Toolbox & nntool \\
\hline Type & Feedforward backpropagation \\
\hline Algorithm & Levenberg-Marquardt \\
\hline Training function & Trainlm \\
\hline $\begin{array}{c}\text { Adoption Learning } \\
\text { function }\end{array}$ & Learngdm \\
\hline Performance function & Mean squared error (MSE) \\
\hline
\end{tabular}

Afterwards, the input-output database is used to train and test the multi-layer neural network using feedforward backpropagation learning algorithm. The data was default splitted into learning and validation. In order to identify the best neural network structure, several numbers of trials were performed for each of the training algorithm to identify number of neurons in the hidden layer and the output layer. The aims of this trials are to obtained low number of mean squared error (MSE) and best correlation coefficient (R). MSE is the average squared difference between outputs and targets and the lower values are better. $\mathrm{R}$ values measure the correlation between outputs and targets with $R$ value of 1 means a close relationship and, 0 a random relationship. Table 5 shows the comparison about the separated network and the MSE value with varying the number of hidden layer from 4 to 14. Table 6 shows the comparison about the separated network in evaluation of $\mathrm{R}$ value.

According to Table 5 and Table 6, hidden layer 10 with separated network is found to be the best solution for the prediction model in this present study. The neural network structure 10-10-1 contributed to the best results with the lowest MSE value for both training and testing data compared than the other hidden layer and combination network. It consisted of ten input neurons in the input layer corresponding to ten cutting parameters, one hidden layer with ten neurons and one output neuron in output layer (corresponding to MRR and surface roughness respectively).

After successful training, the network model described in this study was used to predict the MRR and surface roughness within the trained range. The evaluation of errors that take into consideration between learning and testing step were the value of MSE, R, and relative error percentage. 
Table 5. Comparison between number of hidden layer with separated network (MRR, surface roughness respectively) and combined network (all responses)

\begin{tabular}{|c|c|c|c|c|c|c|}
\hline \multirow{2}{*}{\begin{tabular}{c} 
Numbers $\begin{array}{c}\text { of } \\
\text { neurons } \\
\text { (hidden } \\
\text { layer-x) }\end{array}$ \\
\cline { 2 - 7 }
\end{tabular}} & $\begin{array}{c}\text { MSE } \\
\text { Train }\end{array}$ & MSE Test & $\begin{array}{c}\text { MSE } \\
\text { Train }\end{array}$ & $\begin{array}{c}\text { MSE } \\
\text { Test }\end{array}$ & MSE Train & MSE Test \\
\hline $\mathbf{4}$ & $1.414 \mathrm{E}-2$ & $1.161 \mathrm{E}-2$ & $6.132 \mathrm{E}-4$ & $1.552 \mathrm{E}-1$ & $4.524 \mathrm{E}-22$ & $6.252 \mathrm{E}-2$ \\
\hline $\mathbf{6}$ & $6.250 \mathrm{E}-8$ & $3.900 \mathrm{E}-3$ & $1.224 \mathrm{E}-1$ & $1.133 \mathrm{E}+0$ & $8.953 \mathrm{E}-3$ & $1.344 \mathrm{E}-1$ \\
\hline $\mathbf{8}$ & $2.823 \mathrm{E}-7$ & $3.149 \mathrm{E}-4$ & $2.277 \mathrm{E}-4$ & $5.925 \mathrm{E}-2$ & $6.232 \mathrm{E}-5$ & $1.218 \mathrm{E}-1$ \\
\hline $\mathbf{1 0}$ & $6.244 \mathrm{E}-8$ & $3.427 \mathrm{E}-6$ & $1.217 \mathrm{E}-4$ & $1.346 \mathrm{E}-5$ & $1.125 \mathrm{E}-4$ & $6.537 \mathrm{E}-2$ \\
\hline $\mathbf{1 2}$ & $2.497 \mathrm{E}-3$ & $2.726 \mathrm{E}-2$ & $1.621 \mathrm{E}-2$ & $2.006 \mathrm{E}-2$ & $2.236 \mathrm{E}-3$ & $3.954 \mathrm{E}-2$ \\
\hline $\mathbf{1 4}$ & $3.918 \mathrm{E}-3$ & $2.849 \mathrm{E}-3$ & $6.429 \mathrm{E}+0$ & $6.062 \mathrm{E}+0$ & $9.179 \mathrm{E}-3$ & $7.185 \mathrm{E}-2$ \\
\hline
\end{tabular}

Table 6. Comparison of R value for separated and combined network

\begin{tabular}{|c|c|c|c|c|c|}
\hline & \multicolumn{5}{|c|}{ Correlation Coefficient (R) } \\
\cline { 2 - 6 } & MSE & Training & Validation & Test & All \\
\hline $\begin{array}{c}\text { MRR } \\
\text { Response } \\
(10-10-1 \\
\text { ANN model) }\end{array}$ & $8.2772 \mathrm{E}-07$ & 1 & 1 & 1 & 0.99982 \\
\hline $\begin{array}{c}\text { Surface } \\
\text { Roughness } \\
\text { Response } \\
\text { (10-10-1 } \\
\text { ANN model) }\end{array}$ & $8.3591 \mathrm{E}-05$ & 0.99973 & 1 & 1 & 0.99982 \\
\hline $\begin{array}{c}\text { MRR + } \\
\text { Surface } \\
\text { Roughness } \\
\text { Responses } \\
(10-10-2 \\
\text { ANN model) }\end{array}$ & 0.0018595 & 0.99989 & 0.99865 & 0.99092 & 0.99059 \\
\hline
\end{tabular}

\section{RESULTS AND DISCUSSION}

The results of ANN prediction on the MRR and surface roughness according to input cutting parameters in WEDM process are shown and discussed below.

\subsection{Prediction of MRR and surface roughness by ANN}

ANN method was employed to model the MRR and surface roughness according to the cutting parameters. The performance of the developed network was observed according to the differences of regression correlation coefficient ( $\mathrm{R}$ value) between the output (predicted) and the target (experiment) for the test data and entire data as shown in regression plot for 
all patterns, training, validation and testing (Figure 2 and Figure 3). Figure 2 shows the regression plots for MRR and Figure 3 shows the regression plot for surface roughness. The $\mathrm{R}$ value quantifies how close the output and the target fit the regression line. The $\mathrm{R}$ value always lies between -1 and 1 . If they are not correlated to each other, the $\mathrm{R}$ value would be computed to 0 . If it is 1 , it indicates the perfect correlation between the target values and output. In this study, the correlation coefficient obtained between the entire data set (experimental data) and model predicted values were greater than 0.99 , which showed a good correlation.

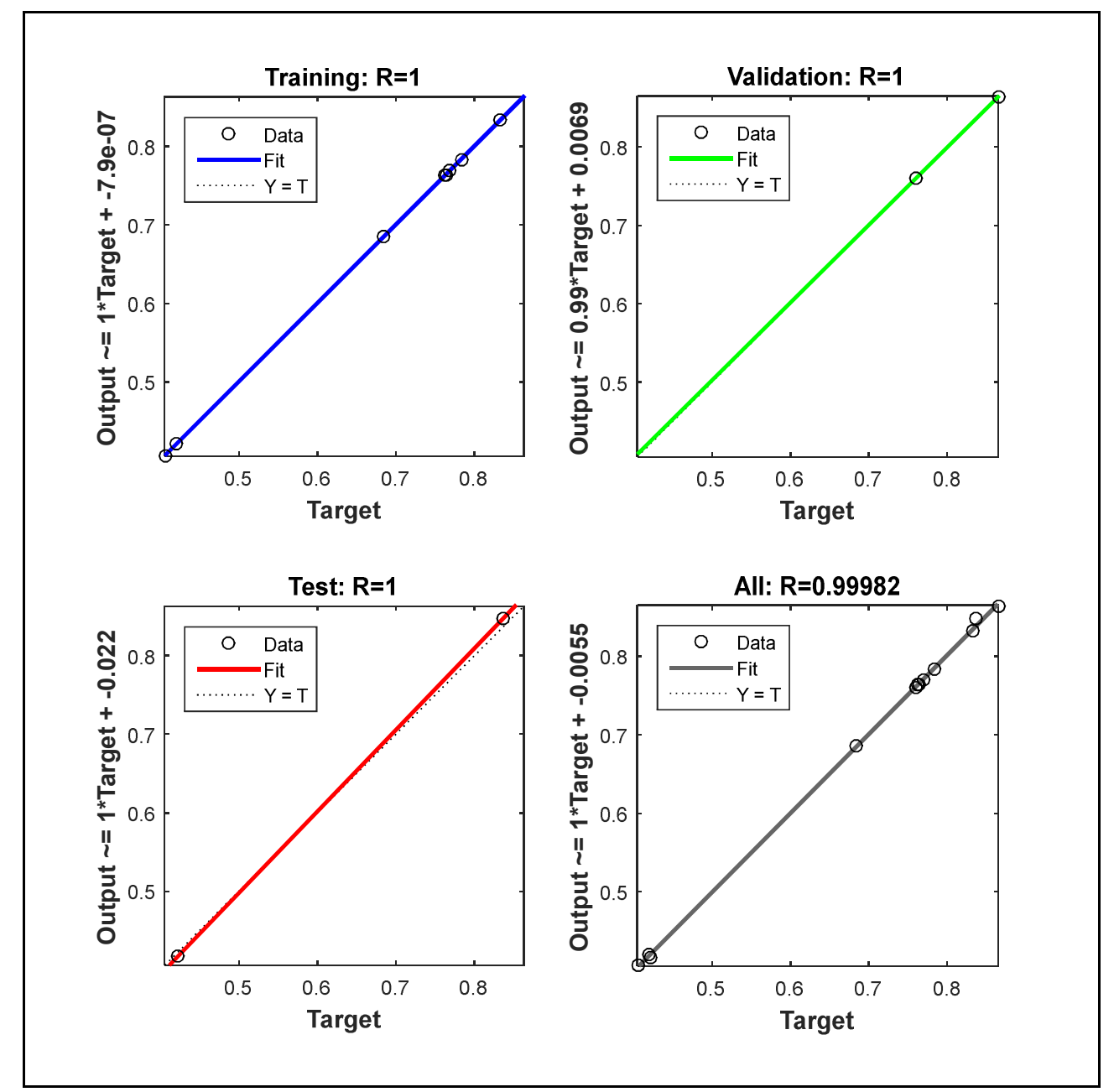

Figure 2. Correlation between the predicted values with training, validation, test and entire data for MRR 


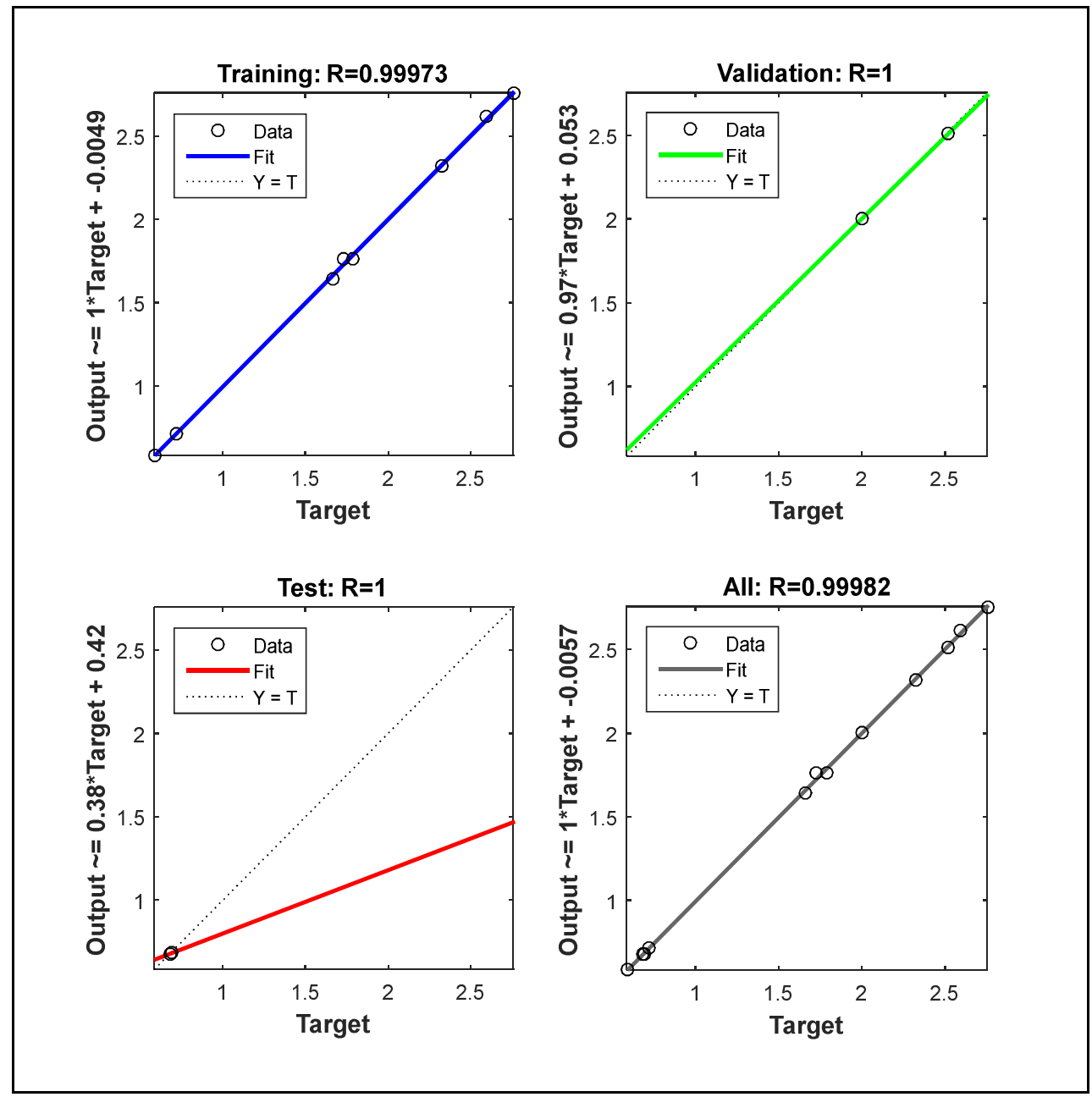

Figure 3. Correlation among the predicted values with training, validation, test and entire data for surface roughness

\subsection{Comparison of ANN and experimental results for MRR}

The developed neural network model has been trained using the selected parameters (Table 4). The mean square error for training model reduced with growing iteration numbers until 16 iterations as shown in Figure 4, but after this point it remained constant. The training of the algorithm was stopped at 32 iterations. It also can be observed from Figure 4, the best validation performance gain at iteration 9. After that, the mean squared error for test and validation model increased gradually until iteration 16 and its remained constant.

The predicted results of the MRR data are shown in Table 5 and illustrated in Figure 5 for ease to make comparison of the results. According to the results, the prediction by neural network method was very close to the experimental. The accuracy of the prediction by neural network method was calculated through percentage of relative error. Relative percentage error is calculated by the differences between the experimental and predicted value to the experimental values and the results shown in Table 5. The average 
relative error among the trials was $0.27 \%$, indicated the trained neural network has excellent accuracy in predicting the MRR in this study.

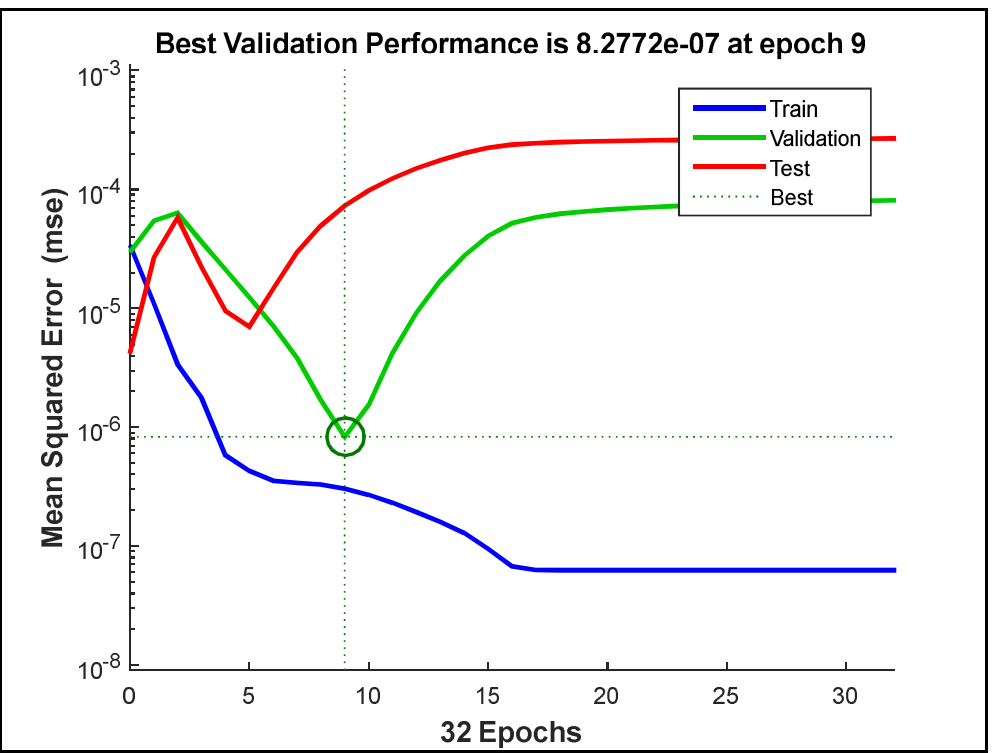

Figure 4. Performance curve plot of mean square error (MSE) with number of epochs for MRR

Table 5. ANN predicted MRR results and its relative error

\begin{tabular}{|c|c|c|c|}
\hline \multirow{2}{*}{ Trials } & \multicolumn{2}{|c|}{ Material Removal Rate $\left.\mathbf{~ m m}^{\mathbf{3}} \mathbf{\text { min}}\right)$} & Relative Error \\
\cline { 2 - 3 } & Experiment & ANN & 1.29 \\
\hline 1 & 0.8366 & 0.8474 & 0.14 \\
\hline 2 & 0.8644 & 0.8631 & 0.01 \\
\hline 3 & 0.8328 & 0.8329 & 0.09 \\
\hline 4 & 0.7832 & 0.7839 & 0.15 \\
\hline 5 & 0.7625 & 0.7636 & 0.01 \\
\hline 6 & 0.7635 & 0.7636 & 0.03 \\
\hline 7 & 0.7690 & 0.7693 & 0.04 \\
\hline 8 & 0.7597 & 0.7594 & 1.28 \\
\hline 9 & 0.4221 & 0.4167 & 0.08 \\
\hline 10 & 0.4205 & 0.4209 & 0.01 \\
\hline 11 & 0.4055 & 0.4055 & 0.10 \\
\hline 12 & 0.6845 & 0.6852 & \\
\hline
\end{tabular}

\subsection{Comparison of ANN and experimental results for surface roughness}

According to Figure 6, the mean square error for train and test model reduced with growing iteration numbers until 1 and remained constant until it was stopped at iteration 3. The results also indicated that the best validation performance gained at initially of the iteration. After that, it increased gradually until iteration 1 and remained constant. 
The predicted results of the surface roughness value are shown are shown in Table 6 and illustrated in Figure 7. The results indicated that the prediction by neural network method was very closed to the experimental with average relative percentage error among the trials is $0.67 \%$. The trained neural network was proved to have an excellent accuracy in predicting the surface roughness.

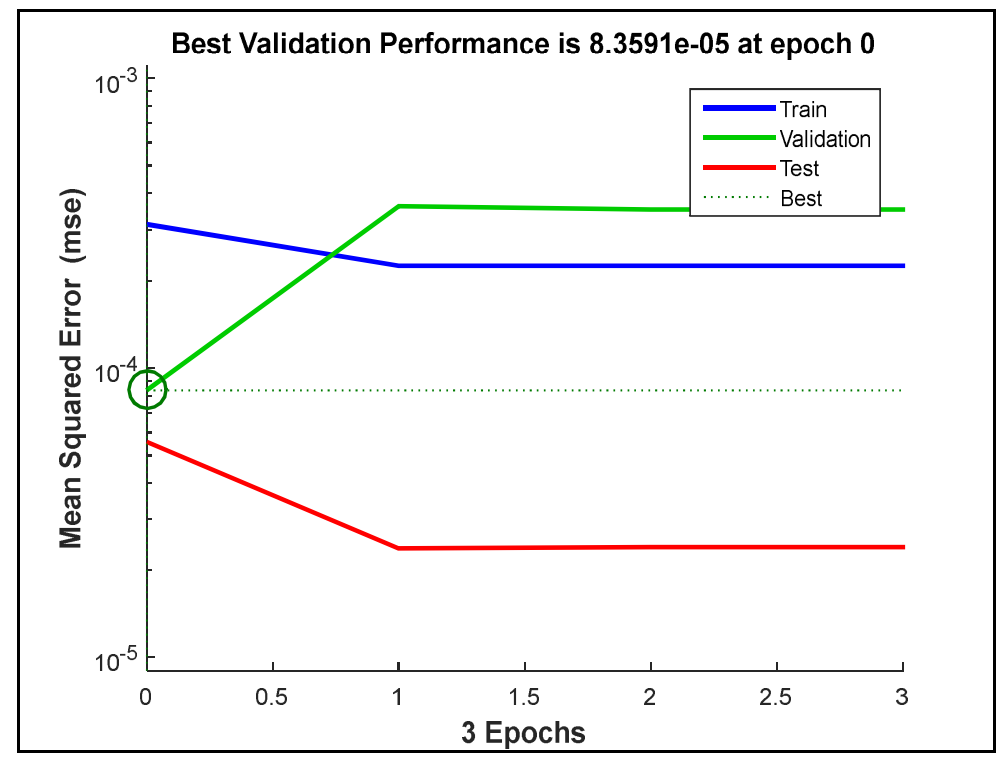

Figure 6. Performance curve plot of mean square error (MSE) with number of epochs for surface roughness

Table 6. ANN predicted surface roughness results and its relative error

\begin{tabular}{cccc}
\multirow{2}{*}{ Trials } & \multicolumn{2}{c}{ Surface Roughness, $(\boldsymbol{\mu m})$} & Relative Error \\
\cline { 2 - 3 } & Experiment & ANN & (\%) \\
\hline 1 & 2.520 & 2.507 & 0.51 \\
2 & 2.756 & 2.756 & 0.00 \\
3 & 2.598 & 2.613 & 0.57 \\
4 & 2.324 & 2.321 & 0.13 \\
5 & 1.728 & 1.760 & 1.83 \\
6 & 1.788 & 1.760 & 1.59 \\
7 & 2.004 & 2.005 & 0.03 \\
8 & 1.662 & 1.640 & 1.31 \\
9 & 0.692 & 0.682 & 1.37 \\
10 & 0.684 & 0.679 & 0.66 \\
11 & 0.584 & 0.584 & 0.00 \\
12 & 0.718 & 0.718 & 0.07 \\
\hline
\end{tabular}




\section{Conclusions}

In this study, the application of ANN technique was carried out in developing a model for prediction the sustainable measures (MRR and surface roughness) with benefits in enhancement of production quantity and product quality. Since it is difficult to understand the natural behavior of WEDM cutting parameter in water-based dielectric, this an artificial intelligence-based model offers the ability to model more complex nonlinearities and interactions. It provides an efficient prediction with great accuracy, proven by the reported average relative error for MRR was $0.27 \%$ and surface roughness was $0.67 \%$ that indicates the developed model using this technique possess great accuracy in predicting the sustainable measures.

\section{Acknowledgements}

The authors would like to thank the financial support of UTeM Zamalah Scheme as well as the facility support by the Faculty of Manufacturing Engineering, Universiti Teknikal Malaysia Melaka (UTeM). This research is also supported by Malaysian Ministry of Higher Education for [Fundamental Research Grant Scheme (FRGS); FRGS/1/2018/TK03/UTEM/02/14].

\section{REFERENCES}

[1] Atzeni E, Bassoli E, Gatto A, Iuliano L, Minetola P, Salmi A, Surface And Sub Surface Evaluation In Coated-Wire Electrical Discharge Machining (WEDM) Of INCONEL ${ }^{\circledR}$ Alloy 718. Procedia CIRP, Vol. 33, pp. 388-393, 2015.

[2] Saedon JB, Jaafar N, Jaafar R, Saad NH, Kasim MS, Modeling And MultiResponse Optimization On WEDM Ti6Al4V. Applied Mechanics and Materials, Vol. 510, pp. 123-129, 2014.

[3] Rahim EA, Sasahara H, Surface Integrity In MQL Drilling NickelBased Superalloy. Key Engineering Materials, Vols 447-448, No. 1, pp. 811-815, 2010.

[4] Gamage JR, De Silva AKM, Assessment of Research Needs For Sustainability of Unconventional Machining Processes. Procedia CIRP, Vol. 26, pp. 385-390, 2015.

[5] Mahalil K, Rahim EA, Mohid Z, Performance Evaluation of Sustainable Coolant Techniques On Burnishing Process. IOP Conference Series: Materials Science and Engineering, Vol. 494, pp. 1-9, 2019.

[6] Kellens K, Renaldi, Dewulf W, Duflou JR, Preliminary Environmental Assessment Of Electrical Discharge Machining. Proceedings of the 18th CIRP International Conference on Life Cycle Engineering, Berlin, pp. 377-382, 2011.

[7] Kou Z, Han F, On Sustainable Manufacturing Titanium Alloy By High-Speed EDM Milling With Moving Electric Arcs While Using Water-Based Dielectric. Journal of Cleaner Production, Vol. 189, pp. 78-87, 2018. 
[8] Ariffin MKAM, Che Hussain HB, Mohamed SB, Sulaiman S, Determining Optimum Electro Discharge Machining Parameters For Drilling of A Small Hole By Utilizing Taguchi Method. Applied Mechanics and Materials, Vol. 564, No. 1, pp. 481-487, 2014.

[9] Singh NK, Pandey PM, Singh KK, Sharma MK, Steps Towards Green Manufacturing Through EDM Process: A Review. Cogent Engineering, Vol. 3, No. 1, pp. 1-13, 2016.

[10] Izamshah R, Akmal M, Kasim MS, Mohamed SB, Experimental Analysis On Parameters Affecting The Material Removal Rate In Wire Electrical Discharge Turning Using The Taguchi Method. International Journal of Mechanical \& Mechatronics Engineering, Vol. 18, No. 5, pp. 75-82, 2018.

[11] Ming W, Zhang Z, Zhang G, Huang Y, Guo J, Chen Y, Multi-Objective Optimization of 3D-Surface Topography of Machining YG15 In WEDM. Materials and Manufacturing Processes, Vol. 29, No. 5, pp. 514$525,2014$.

[12] Saedon JB, Jaafar N, Yahaya MA, Characteristics of Machining Parameters On WEDM Titanium Alloy. Materials Science Forum, Vol. 872, pp. 23-27, 2016.

[13] Sharma N, Raj T, Jangra KK, Parameter Optimization And Experimental Study On Wire Electrical Discharge Machining of Porous Ni 40 Ti 60 Alloy. Proceedings of the Institution of Mechanical Engineers, Part B: Journal of Engineering Manufacture, Vol. 231, No. 6, pp. 956-970, 2017.

[14] Rao RV, Kalyankar VD, Optimization Of Modern Machining Processes Using Advanced Optimization Techniques: A Review. International Journal of Advanced Manufacturing Technology, Vol. 73, Nos. 5-8, pp. 1159-1188, 2014.

[15] Izamshah R, Akmal M, Kasim MS, Sundi SA, Hadzley M, A Statistical Comparison In Selection Of Wire-EDM Process Parameters For Machining Titanium Alloy. Journal of Advanced Manufacturing Technology (JAMT), Vol. 10, No. 2, pp. 45-55, 2016.

[16] Siswoyo A, Arief Z, Sulistijono IA, Application Of Artificial Neural Networks In Modeling Direction Wheelchairs Using Neurosky Mindset Mobile ( EEG ) Device. EMITTER International Journal of Engineering Technology, Vol. 5, No. 1, pp. 170-191, 2017.

[17] Chiroma H, Abdul-Kareem S, Shukri Mohd Noor A, Abubakar AI, Sohrabi Safa N, Shuib L, Fatihu Hamza M, Ya'u Gital A, Herawan T, A Review On Artificial Intelligence Methodologies For The Forecasting Of Crude Oil Price. Intelligent Automation and Soft Computing, Vol. 22, No. 3, pp. 449-462, 2016.

[18] Shandilya P, Jain PK, Jain NK, RSM And ANN Modeling Approaches For Predicting Average Cutting Speed During WEDM Of SiCp/6061 Al MMC. Procedia Engineering, Vol. 64, pp. 767-774, 2013.

[19] Devarasiddappa D, George J, Chandrasekaran M, Teyi N, Application of 
Artificial Intelligence Approach In Modeling Surface Quality of Aerospace Alloys In WEDM Process. Procedia Technology, Vol. 25, No. Raerest, pp. 1199-1208, 2016.

[20] Hasan MS, Ebrahim Z, Wan Mahmood WH, Ab Rahman MN, Sustainable -ERP System: A Preliminary Study On Sustainability Indicators. Journal of Advanced Manufacturing Technology, Vol. 1, pp. 61-74, 2017.

[21] Muthukrishnan N, Davim JP, Optimization Of Machining Parameters Of Al / SiC-MMC With ANOVA And ANN Analysis. Journal of Materials Processing Technology, Vol. 209, No. 1, pp. 225-232, 2009.

[22] Izamshah R, Akmal M, Kasim MS, Sued MK, Sundi SA, Amran M, Parametric Study On Parameter Effects In Hybrid Micro Wire Electrical Discharge Turning. Journal of Advanced Manufacturing Technology (JAMT), Vol. 12, No. 1, pp. 1-12, 2018.

[23] Abu NH, Jaya ASM, Muhamad MR, Performance Analysis Of Neural Network Models For Sustainable Manufacturing Practices (SMP) And Economy Performances. Proceedings of Mechanical Engineering Research Day 2016, Vol. 2016, pp. 46-47, 2016.

[24] Boukezzi F, Noureddine R, Benamar A, Noureddine F, Modelling, Prediction And Analysis of Surface Roughness In Turning Process With Carbide Tool When Cutting Steel C38 Using Artificial Neural Network. International Journal of Industrial and Systems Engineering, Vol. 26, No. 4, pp. 567-583, 2017. 